\title{
Perancangan Aplikasi Media Pembelajaran Pengenalan Hewan Berbasis Virtual Reality Menggunakan Platform Android
}

\author{
I Made Artawan ${ }^{1}$, Made Sudarma ${ }^{2}$, I Made Arsa Suyadnya ${ }^{3}$ \\ Program Studi Teknik Elektro, Fakultas Teknik, Universitas Udayana Denpasar - Bali \\ Email : kadekartawan777@yahoo.com ${ }^{1}$, msudarma@unud.ac.id $^{2}$, arsa.suyadnya@unud.ac.id $^{3}$
}

\begin{abstract}
Abstrak
IImu pengetahuan alam (IPA) merupakan mata pelajaran yang ditujukan agar siswa mempunyai konsep terorganisasi tentang alam sekitar. Mempelajari IPA sebagai cara membantu siswa untuk memahami alam sekitar lebih mendalam. Salah satu materi pelajaran IPA yang diberikan di sekolah dasar kelas IV membahas mengenai pengelompokan hewan berdasarkan jenis makanan. Pada materi pelajaran tersebut siswa diharapkan agar dapat mengetahui perbedaan antara hewan herbivora, karnivora dan omnivora. Saat ini guru-guru di sekolah hanya menggunakan metode pembelajaran konvensional dengan media buku untuk menyampaikan materi. Media buku atau media pembelajaran konvensional tidak dapat memberikan visualisasi secara nyata mengenai bentuk hewan. Berdasarkan permasalahan pembelajaran pengelompokan hewan di sekolah dasar, aplikasi media pembelajaran pengenalan hewan berbasis virtual reality dibuat untuk membantu siswa sekolah dasar dalam mengenal objek hewan. Pengembangan aplikasi dimulai dari tahap konsep, desain, pengumpulan bahan, perakitan, pengujian, hingga tahap distribusi. Aplikasi ini dibangun dengan menggunakan Bahasa pemrograman C\#, google cardboard SDK, software blender dan unity. Adapun hasil yang didapat yaitu sebuah aplikasi yang dapat digunakan sebagai media pembelajaran pengenalan hewan. Dalam aplikasi media pembelajaran pengenalan hewan ini pengguna dapat berjalan, dapat melihat jenis-jenis hewan herbivora, karnivora dan omnivora yang sudah dilengkapi informasi, suara dan animasi. Berdasarkan hasil pengujian dengan metode Black-Box, fungsional aplikasi telah dapat berjalan dengan baik dan berdasarkan pengujian System Usability Scale diperoleh hasil nilai rata-rata dari 20 responden sebesar 80,25 dengan Grade Scale B.
\end{abstract}

Kata Kunci : Google Cardboard, Pengenalan Hewan, Unity, Virtual Reality.

\begin{abstract}
Natural science (IPA) is a subject that is intended to allow students to have an organized concept of the natural surroundings. Learn science as a way of helping students to understand more deeply the natural surroundings. One material science lessons given in fourth grade elementary school to discuss the grouping animals based on the type of food. On the subject matter students are expected to be able to tell the difference between herbivores, carnivores and omnivores. Currently the teachers at the school only uses conventional teaching methods with the book medium for conveying the material. Media books or conventional learning media can not provide a real visualization of the shape of animals. Animal grouping based learning problems in elementary school, learning media applications based animal recognition virtual reality created to help elementary school students in recognizing the object animal. Application development starts from the concept stage, design, collection of materials, assembly, testing, until the distribution phase. This application is built using the programming language C \#, google cardboard SDK, software blender and unity. The result obtained is an application that can be used as a learning medium introduction of animals. In the introduction of animal learning media applications users can run, can see the types of herbivores, carnivores and omnivores are already equipped with information, sound and animation. Based on the test results with the Black-Box, functional applications have been able to run well and based ontest the System Usability Scale result average value of 20 respondents was 80.25 with Scale Grade B.
\end{abstract}

Keywords: Google cardboard, Introduction to Animals, Unity, Virtual Reality.

\section{PENDAHULUAN}

IImu pengetahuan alam (IPA) merupakan mata pelajaran yang ditujukan agar siswa 
mempunyai konsep terorganisasi tentang alam sekitar dari pengalaman melalui serangkain proses ilmiah penyajian gagasan-gagasan. Pada prinsipnya, mempelajari IPA sebagai cara membantu siswa untuk memahami lingkungan alam sekitar lebih mendalam [1]. Dapat dikatakan bahwa IPA merupakan suatu kegiatan yang telah diuji kebenarannya melalui langkah-langkah yang sistematis yang disebut juga dengan metode ilmiah.

Salah satu materi pelajaran IPA yang diberikan di sekolah dasar kelas IV membahas mengenai pengelompokan hewan berdasarkan jenis makanan. Pada materi pelajaran tersebut siswa diharapkan agar dapat mengetahui perbedaan antara hewan herbivora, karnivora dan omnivora. Saat ini guru-guru di sekolah hanya menggunakan metode pembelajaran konvensional dengan media buku untuk menyampaikan materi. Teknik ini dirasa kurang efektif dan interaktif. Akibatnya siswa akan merasa bosan dalam proses pembelajaran. Selain itu, media pembelajaran yang hanya menggunakan buku menyebabkan siswa menjadi kurang paham terhadap materi yang dipelajari, karena media buku atau media pembelajaran konvensional tidak dapat memberikan visualisasi secara nyata mengenai bentuk hewan.

Salah satu pemanfaatan teknologi di bidang multimedia yang berkembang saat ini adalah Virtual reality (VR) atau realitas maya. Virtual Reality adalah teknologi yang mampu membuat pengguna dapat merasakan atau dapat berinteraksi di suatu lingkungan dunia virtual yang disimulasikan dengan komputer atau suatu lingkungan nyata yang ditiru seperti aslinya [2].

Pemanfaatan virtual reality untuk berbagai tujuan telah banyak dilakukan, diantaranya penelitian mengenai aplikasi berbasis virtual reality untuk mendukung terapi fobia laba-laba dengan menggunakan google cardboard. Aplikasi yang dibangun dengan menggunakan unity 3D dan hasil dari penelitian ini adalah berupa simulasi kondisi laba-laba seperti di dunia nyata ke dalam lingkungan 3 dimensi [3]. Penelitian lainnya adalah penelitian mengenai pengembangan museum Virtual interaktif berbasis Virtual Reality pada museum ranggawarsita. Aplikasi yang dibangun berbasis desktop dan hasil dari penelitian ini adalah berupa museum virtual yang dibuat dengan menggunakan game engine yaitu Unity 3D, karakter dibuat menggunakan program blender, dengan beberapa animasi 3D fitur yang ada adalah interaksi pengguna terhadap objek yang dapat menampilkan informasi terhadap objek museum yang ditemui [4].

Berdasarkan permasalahan mengenai pembelajaran pengelompokan hewan di sekolah dasar, pemanfaatan teknologi virtual Reality dapat diterapkan untuk permasalahan tersebut. Pada penelitian ini akan dibangun sebuah aplikasi media pembelajaran pengenalan hewan berbasis virtual Reality. Dalam aplikasi media pembelajaran pengenalan ini pengguna dapat berjalan, dapat melihat jenis - jenis hewan herbivora, karnivora dan omnivora yang sudah dilengkapi informasi, suara dan animasi. Dengan adanya aplikasi ini diharapkan dapat membantu siswa dalam mengenal objek hewan lebih mudah dipahami dengan bentuk visualisasi hewan yang seperti nyata.

\section{KAJIAN PUSTAKA}

\subsection{Media Pembelajaran}

Media Pembelajaran baik hadware maupun software merupakan media yang ditujukan untuk meningkatkan efektivitas proses belajar mengajar. Media pembelajaran berfungsi sebagai alat bantu dalam proses situasi belajar. Media yang menarik dan tepat dapat meningkatkan dan mengarahkan perhatian siswa serta dapat menimbulkan niat belajar [5].

\subsection{Virtual Reality}

Virtual Reality merupakan teknologi yang mampu membuat pengguna dapat berinteraksi dengan dunia lingkungan virtual atau dunia tiruan yang disimulasikan dengan komputer, suatu lingkungan dunia nyata yang ditiru seperti aslinya. Dengan teknologi ini, pengguna dapat berinteraksi dan dapat merasakan melalui indera penglihatan, pendengaran dan sentuhan. Virtual reality juga memungkinkan pengguna akan merasakan seperti berada di lingkungan dunia tiruan tersebut [6].

\subsection{Unity}

Menurut Creighton, unity adalah sebuah teknologi yang mampu meringankan dan memudahkan pengembang game untuk membuat sebuah game. Unity adalah game engine yang mendukung pengembang untuk 
membangun suatu aplikasi dan simulasi. Unity dapat digunakan untuk membuat sebuah game yang bisa digunakan pada perangkat smartphone Android dan komputer [7].

\subsection{System Usability Scale (SUS)}

System Usability Scale merupakan salah satu teknik uji sebuah produk ke pada pengguna yang diterapkan dengan 10 buah pernyataan berbentuk kuisioner dengan 5 buah item penilaian mulai dari sangat setuju sampai sangat tidak setuju. Adapun beberapa pernyataan kuisioner System Usability Scale yang dapat dilihat pada Gambar 1 [8].

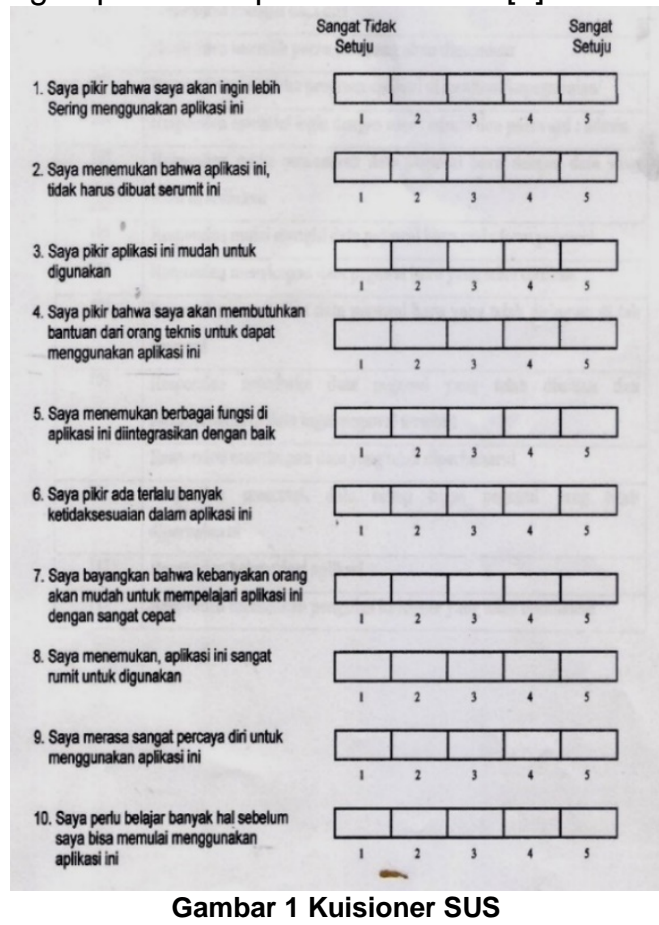

Penggunaan kuisioner SUS membutuhkan paling sedikitnya 20 pengguna yang melingkupi pengguna terakhir sampai pembuat sistem aplikasi. Kuisioner SUS digunakan setelah semua responden menggunakan aplikasi. Penghitungan nilai SUS dilakukan dengan menjumlahkan nilai tiap item. berkisaran dari 1 sampai 5 . Perhitungan bobot untuk item pernyataan ganjil nilai item tersebut adalah hasil dari penilaian dari pengguna untuk item tersebut dikurangi satu. Perhitungan bobot untuk item pernyataan nomor genap nilai item yang didapat adalah hasil dari 5 dikurangi dengan posisi nilai item yang diperoleh dari pengguna. Kemudian jumlahkan nilai total skor 10 item pernyataan dikalikan 2,5 sehingga mendapatkan nilai keseluruhan skor SUS akhir dalam rentang $0-100$. Adapun rentang nilai rerata SUS yang dapat dilihat pada Gambar 2.

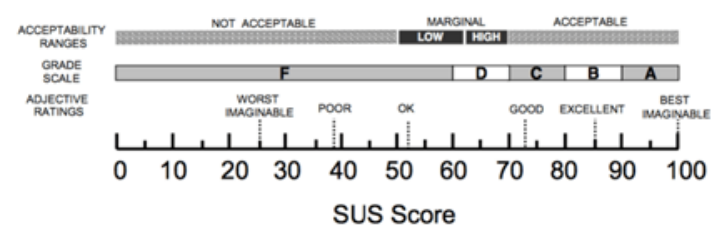

Gambar 2. Rentang Nilai Rerata SUS

\section{METODELOGI PENELITIAN}

Data penelitian ini bersumber dari beberapa buku ilmu pengetahuan alam sekolah dasar kelas IV. Pengumpulan data yang digunakan pada penelitian ini menggunakan metode studi literatur mengumpulkan data dari buku-buku referensi yang digunakan, sebagai acuan membantu dalam pembuatan aplikasi yang akan dibuat pada penelitian ini. Adapun tahapan penelitian seperti :

1. Tahap pertama yang dilakukan yaitu mengidentifikasi masalah, menjabarkan masalah dan membuat batasan masalah.

2. Pengumpulan data berupa studi literatur yang diperoleh dari data-data referensi yang dibutuhkan untuk menunjang penelitian.

3. Menentukan konsep aplikasi yang akan dibangun.

4. Tahap desain perancangan adalah tahap membuat spesifikasi mengenai arsitektur program, gaya.

5. Pengumpulan bahan, tahap ini merupakan tahap lanjutan perancangan.

6. Perakitan atau membangun aplikasi di software unity, pembuatan aplikasi didasarkan pada tahap disain. Perakitan menggunakan Bahasa pemrograman c\#.

7. Pada pengujian ini dilakukan distribusi aplikasi yang sudah jadi ke pengguna mendapatkan hasil feedback menggunakan metode pengujian Usability Testing dan Black-Box.

8. Pengambilan kesimpulan mengenai penelitian.

\subsection{Gambaran Umum Sistem}

Gambaran umum proses penggunaan aplikasi virtual Reality pengenalan hewan yang terjadi antara pengguna dengan aplikasi. 
Dimana user menggunakan smartphone berbasis Android yang sudah dilengkapi dengan aplikasi virtual Reality dengan tambahan kacamata headset atau google cardboard untuk menjalankan aplikasi, sehingga pengguna seakan melihat secara langsung apa yang ditampilkan di aplikasi tersebut. Adapun gambaran umum sistem dapat dilihat pada Gambar 3.

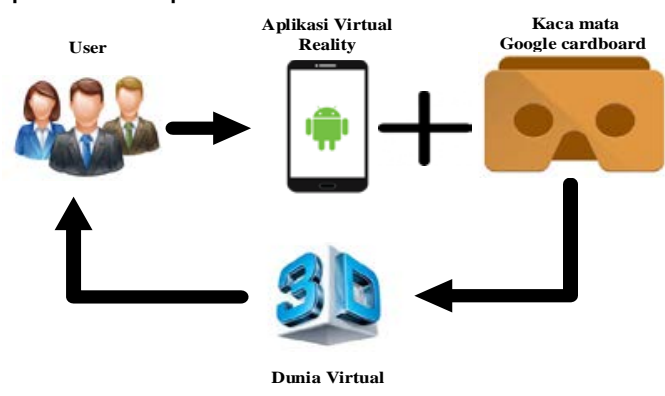

Gambar 3. Gambaran Umum Sistem

Berdasarkan gambar 3 di atas dapat dijelaskan langkah yang akan dilakukan dalam penggunaan aplikasi ini yaitu pertama user menjalankan aplikasi virtual Reality pengenalan hewan. Dimana sebelum masuk ketampilan dunia virtual, akan dimunculkan Splash Screen terlebih dahulu. Kemudian pengguna masuk ke dalam dunia virtual, melihat informasi cara menggunakan aplikasi. Untuk mulai berjalan di dalam dunia virtual, pengguna harus menggeser tombol magnet yang ada di google cardboard sehingga pengguna dapat berjalan, dapat melihat objek hewan. Kemudian pengguna bisa menampilkan informasi hewan serta suara dengan cara mendekati objek hewan tersebut. Jika user ingin menampilkan menu dan memilih menu dengan cara melihat tombol menu ke bawah selama 3 detik.

\subsection{Use Case}

Use case merupakan diagram yang dirancang untuk menunjukan fungsionalitas suatu system aplikasi yang berinteraksi dengan dunia luar yang dapat dilihat pada Gambar 4.

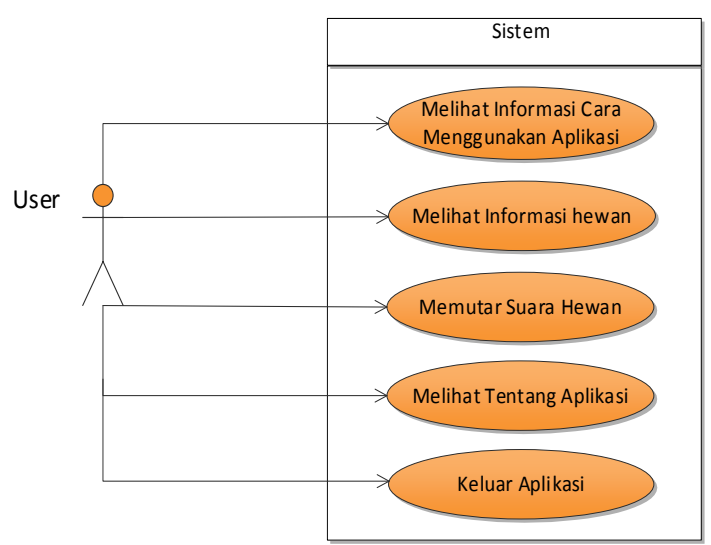

Gambar 4. Use Case

Seperti dilihat pada gambar 4, pada use case dapat dilihat apa saja yang dapat dilakukan oleh user pada saat menggunakan aplikasi virtual reality pengenalan hewan. Terdapat beberapa aktivitas pada aplikasi ini antara lain : melihat informasi cara menggunakan aplikasi, melihat informasi hewan, memutar suara hewan, melihat tentang aplikasi dan keluar aplikasi.

\subsection{Activity Diagram}

Acitivity diagram mengambarkan berbagai aliran aktivitas dalam system aplikasi yang sudah dirancang, bagaimana masingmasing fungsionalitas bekerja dan bagaimana suatu funsionalitas berakhir. Activity diagram memodelkan event yang terjadi pada use case yang dapat dilihat pada Gambar 5 .

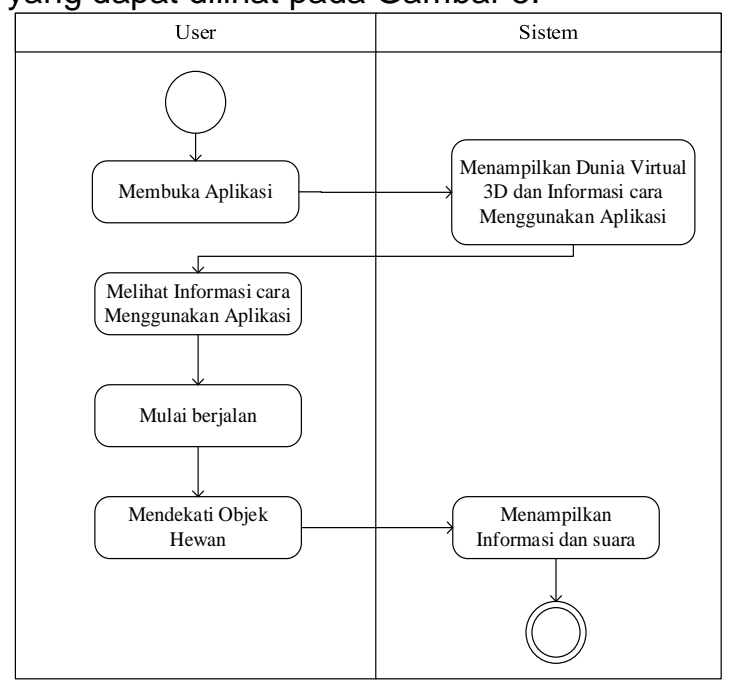

Gambar 5. Activity Diagram

Seperti dilihat pada gambar 5, pada activity diagram terlihat beberapa tahapan yang perlu dijalankan, dimulai dari proses 
membuka aplikasi. Kemudian user melihat informasi cara menggunakan aplikasi. setelah itu, user mulai berjalan mendekati objek hewan lalu sistem akan menampilkan informasi hewan serta suara.

\section{HASIL DAN PEMBAHASAN}

\subsection{Hasil}

Penelitian ini menghasilkan sebuah aplikasi media pembelajaran pengenalan hewan berbasis virtual reality yang dapat di operasikan pada platform mobile Android. Dengan hadirnya aplikasi ini, diharapkan dapat membantu siswa sekolah dasar dalam mengenal objek hewan, dengan penerapan teknologi virtual reality objek hewan bisa di tampilkan seperti aslinya, serta lingkungan dunia virtual yang dihasilkan seperti di dunia nyata. Dalam aplikasi, pengguna dapat melihat jenis-jenis hewan herbivora, karnivora dan ominivora yang sudah dilengkapi informasi, suara dan animasi. Adapun tampilan scene aplikasi dunia virtual pengenalan hewan dapat dilihat pada Gambar 6.

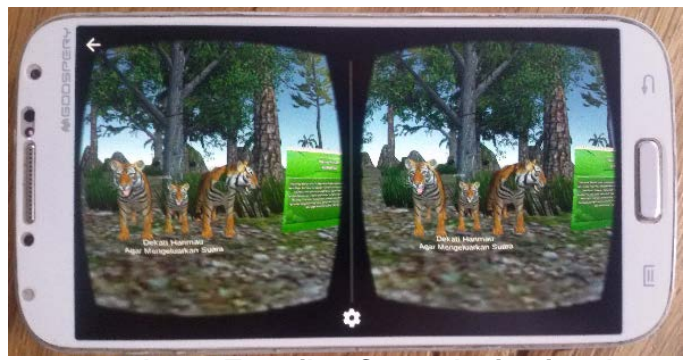

Gambar 6. Tampilan Scene dunia virtual

\subsection{Pembahasan}

Perancangan

aplikasi media pembelajaran pengenalan hewan berbasis virtual reality membahas mengenai tampilan Scene pada aplikasi.

\subsubsection{Scene Splash Screen}

Tampilan Splash screen ini adalah tampilan pertama ketika aplikasi baru dijalankan sebelum masuk ke dalam dunia virtual. Dapat dilihat pada Gambar 7.

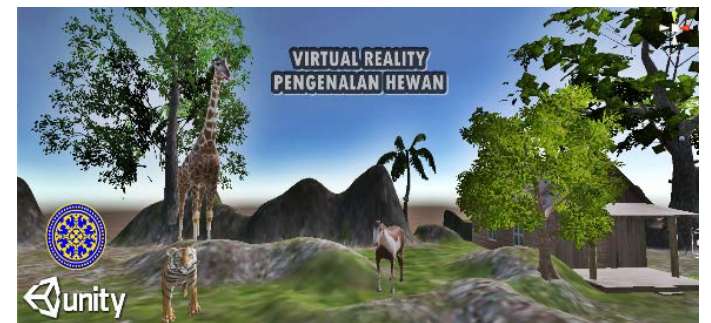

Gambar 7. Tampilan splash screen

Pada gambar 7 dapat dilihat tampilan splash screen yang terdapat judul aplikasi dan logo pengembang. Splash screen akan tampil selama 3 detik setelah itu masuk ke home, dunia virtual.

\subsubsection{Scene Home Dunia Virtual}

Tampilan home, dunia virtual adalah tampilan yang muncul setelah splash screen. Pada menu, home dunia virtual terdapat informasi cara menggunakan aplikasi. Dapat dilihat pada Gambar 8.

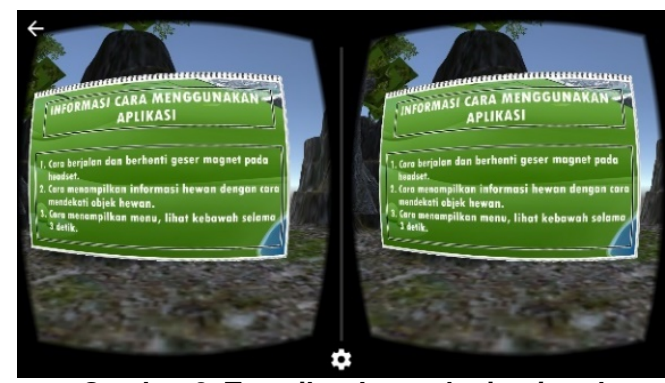

Gambar 8. Tampilan home dunia virtual

Seperti dilihat pada gambar 8, pengguna akan melihat informasi cara menggunakan aplikasi, sebelum mulai berjalan melihat objek hewan di dalam dunia virtual.

\subsubsection{Scene Informasi Hewan}

Tampilan scene informasi hewan merupakan tampilan ketika pengguna menampilkan informasi dari objek hewan. Lebih jelasnya dapat dilihat pada Gambar 9.

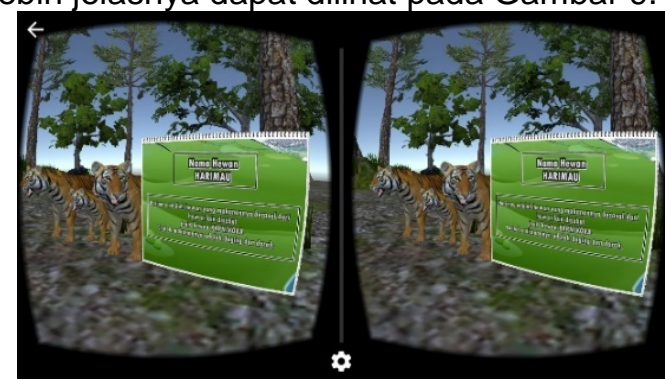

Gambar 9. Tampilan informasi hewan

Pada gambar 9 di atas, cara pengguna menampilkan informasi hewan dengan cara mendekati objek hewan sehingga informasi hewan akan ditampilkan.

\subsubsection{Scene fitur Suara Hewan}

Tampilan scene fitur suara hewan merupakan fitur ketika pengguna ingin 
mengetahui suara dari objek hewan. Lebih jelasnya dapat dilihat pada Gambar 10.

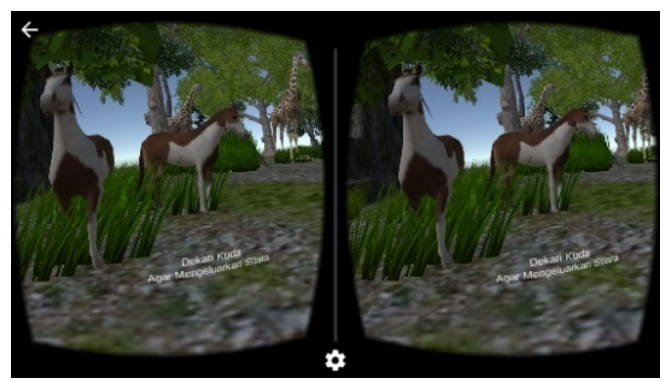

Gambar 9. Tampilan fitur suara hewan

Seperti dilihat pada gambar 10, cara pengguna memutar suara dari objek hewan, pengguna harus mendekati objek hewan tersebut.

\subsubsection{Scene Tombol Menu}

Tampilan scene tombol menu merupakan sebuah tombol untuk menampilkan menu di dalam dunia virtual. Tombol menu berada di bawah pengguna. Pengguna dapat memilih menu dengan cara melihat tombol menu selama 3 detik. Dapat dilihat pada Gambar 11 dan 12.

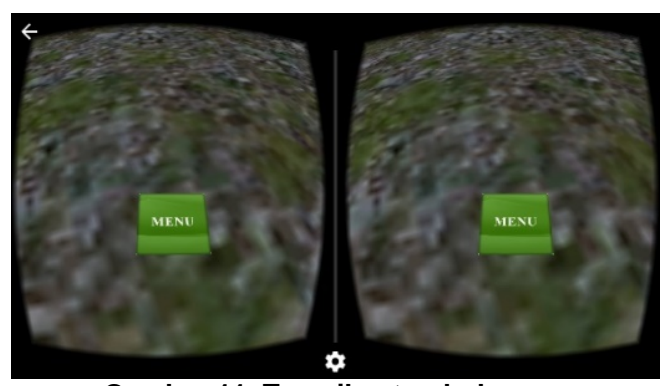

Gambar 11. Tampilan tombol menu

Setelah pengguna melihat tombol menu selama 3 detik, menu pilihan akan muncul seperti pada Gambar 12.

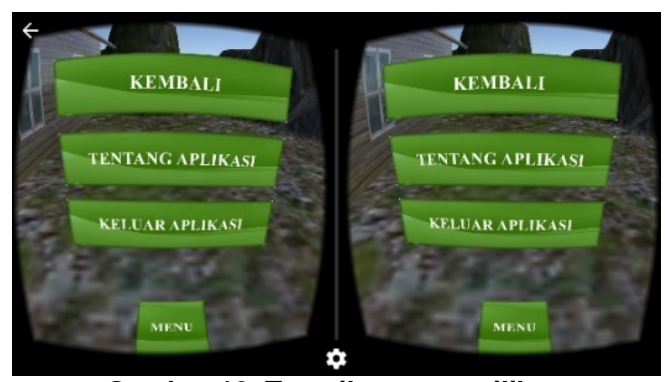

Gambar 12. Tampilan menu pilihan

Untuk memilih menu pilihan di dalam dunia virtual pengguna harus melihat menu pilihan selama 3 detik, maka menu akan muncul seperti pada Gambar 13.

\subsubsection{Scene Tentang Aplikasi}

Tampilan scene tentang aplikasi merupakan tampilan menu informasi pembuat aplikasi. Dapat dilihat pada Gambar 13.

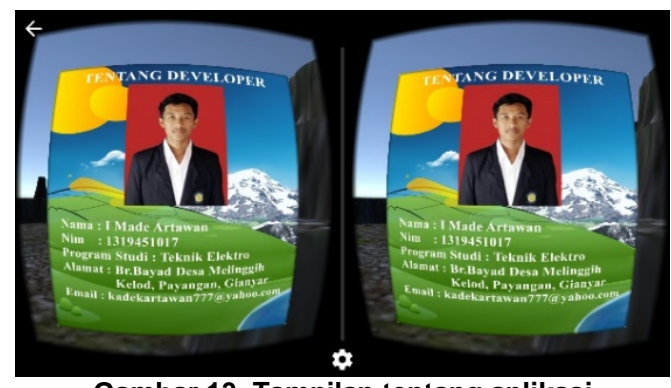

Gambar 13. Tampilan tentang aplikasi

Pada tampilan menu informasi tentang aplikasi terdapat identitas pengembang aplikasi.

Pengujian system aplikasi pada penelitian ini dilakukan dengan dua metode yakni Black-box dan System Usability scale. Berdasarkan hasil pengujian dengan metode black-box keseluruhan fungsional aplikasi pengenalan hewan berfungsi dengan baik.

Pengujian kedua menggunakan metode system usability scale dilakukan dengan memberikan kuisioner kepada dua puluh (20) siswa sekolah dasar kelas IV. Masing-masing responden diberikan 10 buah pernyataan yang dapat dilihat pada Tabel 1.

Tabel 1. Kuisioner SUS
\begin{tabular}{|c|l|c|c|c|c|c|}
\hline \multirow{2}{*}{ No } & Pernyataan & $\begin{array}{l}\text { Sangat } \\
\text { Tidak } \\
\text { Setuju }\end{array}$ & & & & $\begin{array}{l}\text { Sangat } \\
\text { Setuju }\end{array}$ \\
\cline { 3 - 7 } & 1 & 1 & 2 & 3 & 4 & 5 \\
\hline 1 & $\begin{array}{l}\text { Saya pikir saya mungkin } \\
\text { akan menggunakan } \\
\text { aplikasi ini secara lebih } \\
\text { sering }\end{array}$ & & & & & \\
\hline
\end{tabular}




\begin{tabular}{|c|l|l|l|l|l|l|}
\hline 2 & $\begin{array}{l}\text { Menurut saya aplikasi ini } \\
\text { terlalu kompleks }\end{array}$ & & & & & \\
\hline 3 & $\begin{array}{l}\text { Saya pikir aplikasi ini } \\
\text { mudah digunakan }\end{array}$ & & & & & \\
\hline 4 & $\begin{array}{l}\text { Saya pikir saya } \\
\text { membutuhan bantuan } \\
\text { dari tekniksi untuk bisa } \\
\text { menggunakan aplikasi ini }\end{array}$ & & & & & \\
\hline 5 & $\begin{array}{l}\text { Saya Menemukan } \\
\text { berbagai fungsi dalam } \\
\text { aplikasi ini terintegrasi } \\
\text { dengan baik }\end{array}$ & & & & & \\
\hline 6 & $\begin{array}{l}\text { Saya pikir terlalu banyak } \\
\text { hal di aplikasi ini yang } \\
\text { tidak konsekuen }\end{array}$ & & & & & \\
\hline 7 & $\begin{array}{l}\text { Saya akan } \\
\text { membayangkan sebagian } \\
\text { besar orang akan belajar } \\
\text { untuk memakai aplkasi ini } \\
\text { secara cepat }\end{array}$ & & & & & \\
\hline 8 & $\begin{array}{l}\text { Saya menemukan } \\
\text { aplikasi ini sulit untuk } \\
\text { digunakan }\end{array}$ & & & & & \\
\hline 9 & $\begin{array}{l}\text { Saya merasa sangat } \\
\text { yakin untuk } \\
\text { menggunakan aplikasi ini }\end{array}$ & & & & & \\
\hline 10 & $\begin{array}{l}\text { Saya butuh belajar } \\
\text { banyak sebelum } \\
\text { menggunakan aplikasi ini }\end{array}$ & & & & & \\
\hline
\end{tabular}

Hasil pengujian usability testing melalui kuisioner yang didapat dari 20 responden siswa sekolah dasar seperti pada Tabel 2.

Tabel 2. Hasil pengujian usability

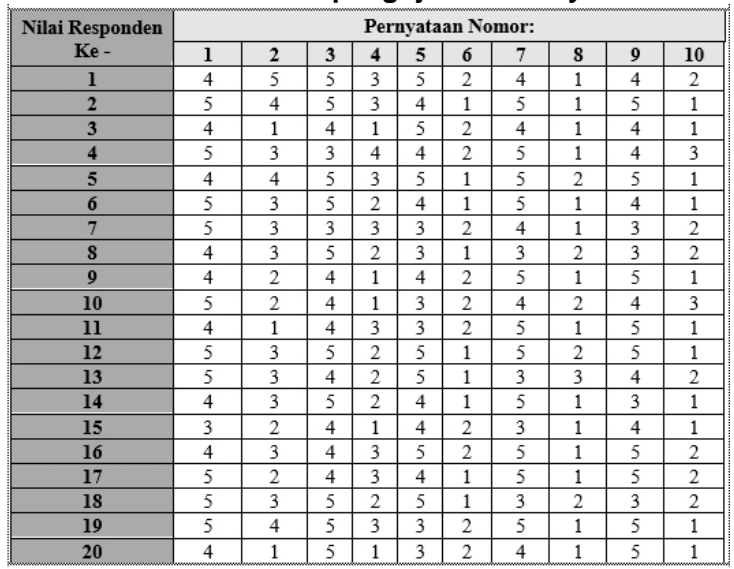

Kuisioner yang telah dibagikan kepada siswa sekolah dasar kemudian diolah datanya menggunakan system usability scale sehingga mendapatkan hasil yang dapat dilihat pada Tabel 3.
Tabel 3. Hasil pengujian aplikasi pengenalan hewan dengan SUS

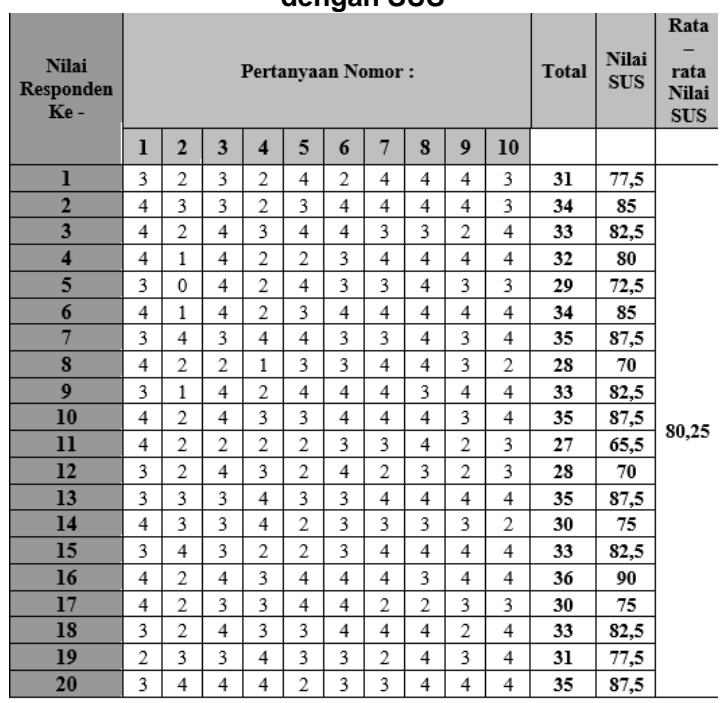

Dari hasil tabel di atas, perangkat lunak mempunyai kualitas yang baik bila berada pada score 70 ke atas. Untuk kasus ini nilai SUS yang didapat dari rata-rata nilai yang didapat dari 20 responden sebesar 80,25. Hasil tersebut menunjukan bahwa sistem memiliki tingkat usabilitas di atas rata-rata karena berada di atas angka 70. Berdasarkan nilai SUS tersebut, maka Aplikasi Media Pembelajaran Pengenalan Hewan Berbasis virtual reality Menggunakan Platform Android yang berarti bernilai Grade Scale = B, Adjective Rating = Excellent jika dikonversikan menurut standar brooke (1996) masuk dalam kategori Acceptable jika dikonversikan menurut kisaran Rating penerimaan.

\section{KESIMPULAN}

Berdasarkan hasil dan pembahasan mengenai aplikasi media pembelajaran pengenalan hewan berbasis virtual reality menggunakan platform Android diperoleh beberapa simpulan sebagai berikut :

1. Aplikasi ini dapat menampilkan visualisasi objek hewan seperti aslinya dan dapat memberikan informasi hewan serta suara.

2. Aplikasi dapat dijalankan pada smartphone berbasis Android jelly bean 4.1 .2 yang memanfaatkan sensor gyroscope pada smartphone Android sebagai kontrol aplikasi.

3. Aplikasi pengenalan hewan berbasis virtual reality menggunakan platform 
Android berhasil dibangun sesuai dengan yang direncanakan dengan menggunakan Unity Engine.

4. Berdasarkan hasil pengujian dengan metode Black-Box, keseluruhan fungsionalitas aplikasi telah berjalan dengan baik. Selain itu, berdasarkan nilai rata-rata pengujian menggunakan System Usability Scale (SUS), maka dapat diartikan Aplikasi Media Pembelajaran Pengenalan Hewan Berbasis Virtual Reality dibangun memiliki nilai sebesar 80,25 yang berarti Adjective Ratings = Excellent dengan Grade Scale $=B$ dan Acceptability Ranges $=$ Acceptable .

\section{DAFTAR PUSTAKA}

[1] Depdiknas, Kurikulum 2004 Standar Kompetensi Mata Pelajaran IImu Pengetahuan Alam Sekolah Dasar. Jakarta : Depdiknas, 2003.

[2] J. Psotka. Immersive Tutoring Systems, Springer : Virtual Reality and Education and Training, 1994.

[3] P. Nugraha, Penerapan Teknologi Virtual Reality Pada Perangkat Bergerak Berbasis Android Untuk Mendukung Terapi Laba-laba. Surabaya : Institut Teknologi Sepuluh Nopember, 2017.

[4] S. Vidiardi, Pengembangan Museum Virtual Interaktif Menggunakan Teknologi Desktop Virtual Reality Pada Museum Ranggawarsita. Semarang : Universitas Negeri Semarang, 2015.

[5] S. Mulyani, Johar. H. Permana. Strategi Belajar Mengajar. Bandung: CV. Maulana, 2011.

[6] L. Zhang. G. Zheng. The virtual campus scene based on VRML. International Conference on Multimedia Technology : IEEE Conference Publications, 2011.

[7] H. Creighton. Unity 3D Game Development by Example. Birmingham : Packt Publishing Limited, 2008.

[8] J. Brooke. (SUS) - dirty usability scale and A quick. Beaconsfield : Redhatch Consulting Ltd, 1996. 